\title{
Molecular genetics of human prostate cancer
}

\author{
Mark A Rubin ${ }^{1}$ and Angelo M De Marzo ${ }^{2,3,4}$ \\ ${ }^{1}$ Department of Pathology, Brigham and Women's Hospital, Boston, MA, USA; ${ }^{2}$ Harvard Medical School, \\ Boston, MA, USA; ${ }^{3}$ Department of Urology and ${ }^{4}$ Department of Oncology, The Johns Hopkins Medical \\ Centers, Johns Hopkins University, Baltimore, USA
}

\begin{abstract}
Multiple factors contribute to the high incidence and prevalence of prostate cancer including race, ethnicity, diet, environment, widespread awareness through prostate-specific antigen screening and genetics. Linkage analysis has identified several candidate sites for hereditary prostate cancer gene loci. Molecular studies have also identified genes that are frequently altered in sporadic prostate cancer. It appears that due to the heterogeneity of prostate cancer, multiple genes may be involved in the neoplastic process.

Modern Pathology (2004) 17, 380-388, advance online publication, 30 January 2004; doi:10.1038/modpathol.3800051
\end{abstract}

Keywords: prostate cancer; hereditary prostate cancer; androgen receptor; microarray; molecular genetics; review

In developed countries, prostate cancer is the most commonly diagnosed nonskin malignancy in males. It is estimated that one in six males will be diagnosed with prostate cancer during their lifetime. Multiple factors contribute to the high incidence and prevalence of prostate cancer. Risk factors include age, family history, and race. Environmental exposures are clearly involved as well. Although the exact exposures that increase prostate cancer risk are unclear, diet (especially those high in animal fat such as red meat as well as those with low levels of antioxidants such as selenium and vitamin E), job/ industrial chemicals, sexually transmitted infections, and chronic prostatitis have been implicated to varying degrees. The marked increase in incidence in prostate cancer that occurred in the mid1980s, which subsequently leveled off in the mid- to late-1990s, indicates that widespread awareness and serum prostate-specific antigen screening can produce a transient marked increase in prostate cancer incidence. This review will examine recent developments in understanding the molecular basis of prostate cancer and some tools that should help us in future investigations.

Correspondence: Dr MA Rubin, MD, Department of Pathology, Brigham \& Women's Hospital, 75 Francis Street, Boston, MA 02115, USA.

E-mail: marubin@partners.org Website: http://rubinlab.bwh. harvard.edu

Received and accepted 14 July 2003; published online 30 january 2004

\section{Hereditary prostate cancer}

Currently, the evidence for a strong genetic component is compelling. Observations made in the 1950s by Morganti et al ${ }^{1}$ suggested a strong familial predisposition for prostate cancer. Strengthening the genetic evidence is a high frequency for prostate cancer in monozygotic as compared to dizygotic twins in a study of twins from Sweden, Denmark, and Finland. ${ }^{2}$ However, unlike the successful mapping and cloning of BRCA1 and BRCA2, which explain a large proportion of hereditary breast cancers, genes conferring susceptibility to prostate cancer have been more elusive. Work over the past decade using genomewide scans in prostate cancer families has identified highrisk alleles, displaying either an autosomal dominant or X-linked mode of inheritance for a hereditary prostate cancer gene, from at least seven candidate genetic loci (Table 1). Of these loci, three candidate genes have been identified, HPC2/ELAC2 on $17 \mathrm{p}^{3}$ and RNASEL on $1 \mathrm{q} 25,{ }^{4}$ and MSR1 on $8 \mathrm{p} 22-23 .{ }^{5}$ In terms of ELAC2, while an initial attempt to confirm these findings was promising, ${ }^{6}$ more recent reports find little evidence that ELAC2 is linked to hereditary or sporadic prostate cancer. ${ }^{7-10}$ RNASEL (encoding ribonuclease L) is a ubiquitously expressed latent endoribonuclease involved in the mediation of the antiviral and proapoptotic activities of the interferon-inducible 2-5A system. $^{11,12}$ Work now from several groups demonstrates that the reduction of RNASEL activity through mutation leads to decreased enzymatic activity. ${ }^{4,13-15}$ Most recent work suggests that approximately $13 \%$ of prostate cancer cases in the population may be attributable to this 
mutation, ${ }^{4}$ although another recent study only found mutations in hereditary cases and not sporadic cases of prostate cancer. ${ }^{16}$ This example of a novel mutation, which is not associated with complete loss of protein production but a decrease in its activity, demonstrates the complexity in understanding the development and progression of cancer. Furthermore, an RNASEL knockout mouse exists, which is devoid of any prostate-related phenotype. However, this mouse is susceptible to infections, an interesting observation given the increasing interest in proliferative inflammatory atrophy (PIA) as a putative precursor lesion in the development of prostate cancer. The other recently observed hereditary gene, MSR1, is a macrophagespecific receptor, which can bind polyanionic ligands, including Gram-negative and Gram-positive bacteria. MSR1 knockout mice also have a reduced capacity to eradicate pathogens. ${ }^{5}$

It is clear, however, that these three genes do not account for the majority of hereditary prostate cancer cases. In addition, more than 10 other loci have been implicated by at least some groups. The discovery of highly penetrant prostate cancer genes has been particularly difficult for at least two main reasons. First, due to the advanced age of onset (median 60 years), identification of more than two generations to perform molecular studies on is difficult. Second, given the high frequency of prostate cancer, it is likely that cases considered to be hereditary during segregation studies actually represent phenocopies; currently, it is not possible to distinguish sporadic (phenocopies) from hereditary cases in families with high rates of prostate cancer. In addition, hereditary prostate cancer does not occur in any of the known cancer syndromes and does not have any clinical (other than a somewhat early age of onset at times) or pathologic characteristics to allow researchers to distinguish it from sporadic cases. ${ }^{17}$ It is hoped that the formation of large international consortia that are collaborating and pooling families will provide some relief to these problems. Perhaps even more important in terms of inherited susceptibility for prostate cancer are common polymorphisms in a number of low penetrance alleles of other genes-the so-called genetic modifier alleles. The list of these variants is long, but the major pathways currently under examination include those involved in androgen action, DNA repair, carcinogen metabolism, and inflammation pathways. ${ }^{18,19}$ It is widely assumed that the specific combinations of these variants, in the proper environmental setting, can profoundly affect the risk of developing prostate cancer.

\section{Early molecular alterations in prostate cancer progression}

Pathologists have long recognized focal areas of epithelial atrophy in the prostate. ${ }^{20-22}$ These focal areas of epithelial atrophy, distinct from the diffuse atrophy seen after androgen deprivation, most often appear in the periphery of the prostate, where prostate cancers typically arise. ${ }^{20,23-27}$ Epithelial atrophy may be associated with acute or chronic inflammation, contain proliferative epithelial cells, and may show morphological transitions in continuity with high-grade prostatic intraepithelial neoplasia (PIN) lesions, a putative prostate cancer precursor. ${ }^{27,28}$ A transition from these atrophic lesion to carcinoma, with little or know recognizable PIN component can be observed. ${ }^{22,29,30}$ Focal atrophy of the prostate exists as a spectrum of morphologies and areas containing it in the prostate can be quite extensive. Since these lesions have also been shown to have a higher proliferation index, ${ }^{25-27,31}$ they have been termed PIA lesions. ${ }^{27} \mathrm{In}$ support of PIA as a prostate cancer precursor, chromosome 8 gain, detected by fluorescence in situ hybridization (FISH) with a chromosome 8 centromere probe, was found in human PIA, PIN, and prostate cancer. ${ }^{31,32}$ Others have recently documented rare p53 mutations in one variant of PIA, ${ }^{33}$ and work from one author group (ADM) shows that approximately $6 \%$ of PIA lesions show evidence of somatic methylation of the GSTP1 gene promoter. ${ }^{34}$ Focal atrophy lesions may arise either as a consequence of epithelial damage from infection, ischemia, or toxin exposure or as a direct consequence of inflammatory oxidant damage to the epithelium. ${ }^{27}$ Regardless of the etiology of PIA, the epithelial cells in these lesions exhibit molecular signs of stress, expressing high levels of GSTP1, GSTA1, and cyclooxygenase 2 (COX-2). ${ }^{27,28,35,36}$ There is also mounting evidence that the atrophic

Table 1 Prostate cancer susceptibility loci identified by linkage analysis

\begin{tabular}{|c|c|c|c|c|}
\hline Susceptibility loci & Locus & Mode & Putative gene & Reference \\
\hline HPC1 & 1q24-25 & $\mathrm{AD}$ & $R N A S E L^{4}$ & Smith et al. ${ }^{106}$ \\
\hline PCAP & $1 \mathrm{q} 42.2-43$ & $\mathrm{AD}$ & ? & Berthon et al. ${ }^{107}$ \\
\hline$C A P B$ & 1p36 & $\mathrm{AD}$ & ? & Gibbs et al. ${ }^{108}$ \\
\hline$H P C X$ & $\mathrm{Xq} 27-28$ & X-linked/AR & ? & $\mathrm{Xu}$ et al. ${ }^{109}$ \\
\hline HPC2O & $20 q 13$ & $\mathrm{AD}$ & $?$ & Berry et al. ${ }^{110}$ \\
\hline \multirow{2}{*}{ HPC2 } & $17 p$ & $\mathrm{AD}$ & $H P C 2 / E L A C 2^{3}$ & Tavtigian et al. ${ }^{3}$ \\
\hline & $8 p 22-23$ & $\mathrm{AD}$ & MSR1 & $\mathrm{Xu}$ et al. ${ }^{5}$ \\
\hline
\end{tabular}

Mode $=$ suggested mode of inheritance; $\mathrm{AD}=$ autosomal dominant; $\mathrm{AR}=$ autosomal recessive 
luminal cells in PIA represent a form of intermediate epithelial cell ${ }^{37}$ - similar to cells postulated to be the targets of neoplastic transformation in the prostate. $^{38-41}$ Therefore, both PIA and high-grade PIN may represent steps along a pathway in the progression to invasive prostate cancer (Figure 1). However, it is not clear if they represent separate pathways or steps along the same pathway.

\section{Chromosomal Instability and Telomeres}

Chromosomal instability is an important molecular mechanism during the pathogenesis of malignant transformation in human epithelial tissues, ${ }^{42}$ yet the molecular mechanisms responsible for chromosome destabilization during carcinogenesis are largely unknown. One route to chromosomal instability is through defective telomeres. ${ }^{43,44}$ Telomeres, which consist of multiple repeats of a 6-base-pair unit (TTAGGG), complexed with several different binding proteins, protect chromosome ends from fusing with other chromosome ends or other chromosomes containing double-strand breaks. ${ }^{45}$ However, in the absence of compensatory mechanisms, telomeric DNA is subject to loss due to cell division and possibly oxidative damage. Telomere shortening leads to chromosomal instability that, in mouse models, causes an increased cancer incidence that is likely a result of chromosome fusions, subsequent breakage, and rearrangement. ${ }^{46,47}$ Telomeres within human carcinomas are often found to be abnormally

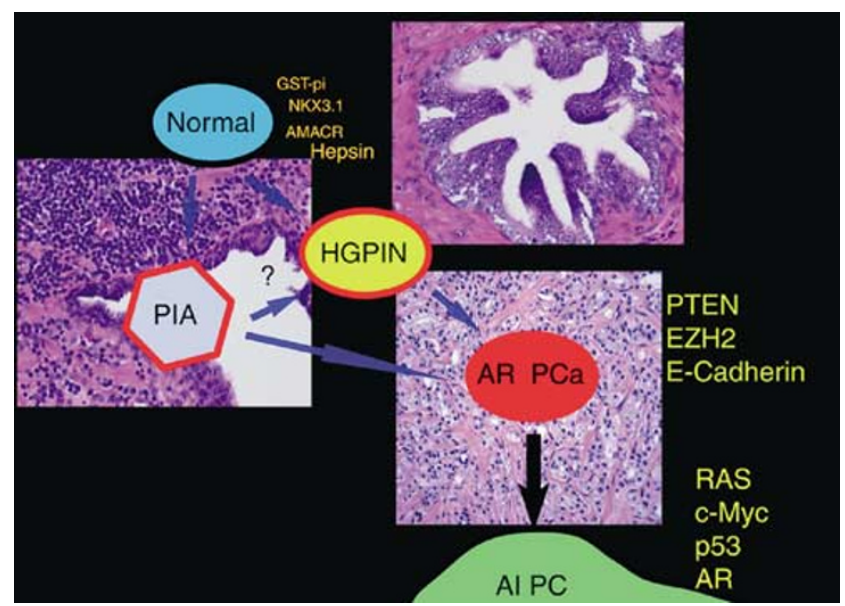

Figure 1 Prostate Cancer Progression. This schematic illustrates the putative steps in the development of prostate cancer. Normal appearing prostate epithelium may develop into clinically localized androgen responsive prostate cancer (AR PCa) through one or two pathways. Normal epithelium may undergo molecular alterations in caretaker genes such as GST-pi or NKX3.1 and develops into the intraepithelial neoplastic lesion, high-grade prostatic intraepithelial neoplasia (PIN). This process may also proceed through proliferative inflammatory atophy (PIA). Alternatively, AR PCA may develop through more than one pathway arising from PIA and high-grade PIN. Multiple genes have been found to be altered in advanced hormone refractory prostate cancer including PTEN, EZH2, and p53. Multiple mutations in the androgen receptor have also been identified. reduced in length. In recent work, the telomeres from prostate cancer were consistently shorter than those from cells in either of the adjacent normal prostate tissue. ${ }^{48,49}$

Most carcinomas arise from preinvasive intra epithelial precursor lesions. ${ }^{50}$ These lesions show morphological features and molecular alterations characteristic of malignant neoplasia, including genetic instability ${ }^{51}$ but occur within pre-existing epithelia and are confined within the basement membrane. If genetic instability helps to drive cancer formation, and telomeres shortening is a major mechanism leading to genetic instability, then telomere shortening should be present at the intraepithelial phase of carcinoma. Recently, an in situ telomere FISH technique was employed to demonstrate telomere shortening in the majority of high-grade PIN lesions, which are thought to be cancer precursor lesions of the prostate. ${ }^{52}$ Interestingly, the telomere shortening found in high-grade PIN was restricted to the luminal cells and was not present in the underlying basal cells. This finding suggests that basal cells are not the direct precursor cells to high-grade PIN, but supports the concept that that cells with an intermediate luminal cell phenotype are the likely direct target cell of transformation in the prostate. Thus, telomere shortening is a prevalent biomarker in human prostate neoplasia occurring early in the process of prostate carcinogenesis.

\section{Molecular alterations in sporadic prostate cancer}

While mutations in any of the classic oncogenes and tumor suppressor genes are not found in high frequency in primary prostate cancers, a large number of studies have identified nonrandom somatic genome alterations. Using comparative genomic hybridization (CGH) to screen the DNA of prostate cancer, the most common chromosomal alterations in prostate cancer are losses at $1 p, 6 q, 8 p$, $10 \mathrm{q}, 13 \mathrm{q}, 16 \mathrm{q}$, and $18 \mathrm{q}$ and gains at $1 \mathrm{q}, 2 \mathrm{p}, 7,8 \mathrm{q}, 18 \mathrm{q}$, and Xq. ${ }^{53-56}$ Numerous genes have now been implicated in prostate cancer progression. Several genes have been implicated in the earliest development of prostate cancer (Table 2). The pi-class of glutathione $S$-transferase (GST), which plays a caretaker role by normally preventing stress-related damage, demonstrates hypermethylation in a high percentage of prostate cancers, thus preventing the expression of this protective gene. ${ }^{57-59}$ NKX3.1, a homeobox gene located at $8 \mathrm{p} 21$, has also been implicated in prostate cancer. $^{60-63}$ Although no mutations have been identified in this gene, ${ }^{61}$ recent work suggests that decreased expression is associated with prostate cancer progression. ${ }^{62}$ PTEN, a tumor suppressor gene located at 10q23, was originally found to be mutated in primary brain tumors and breast and prostate cancer cell lines. ${ }^{64,65}$ 
Table 2 Selected genes associated with prostate cancer progression

\begin{tabular}{|c|c|c|c|c|}
\hline Abbreviation & Gene name(s) & Locus & Functional role & Molecular alteration \\
\hline GST-pi & Glutathione $S$-transferase pi & $11 q 13$ & Caretaker gene & Hypermethlyation \\
\hline NKX3.1 & NK3 transcription factor homolog A & $8 \mathrm{p} 21$ & Homeobox gene & No mutations \\
\hline PTEN & $\begin{array}{l}\text { Phosphatase and tensin homolog } \\
\text { (mutated in multiple advanced cancers } \\
\text { 1) }\end{array}$ & $10 q 23.3$ & Tumor supressor gene & $\begin{array}{l}\text { Mutations and haplotype } \\
\text { insufficiency }\end{array}$ \\
\hline$A M A C R$ & Alpha-methylacyl-CoA racemase & $5 \mathrm{p} 13.2-\mathrm{q} 11.1$ & $\begin{array}{l}\beta \text {-Oxidation of branched-chain fatty } \\
\text { acids }\end{array}$ & Overexpressed in PIN/Pca \\
\hline Hepsin & Hepsin & 19q11-q13.2 & Transmembrane protease, serine 1 & Overexpressed in PIN/Pca \\
\hline$K L F-6$ & Kruppel-like factor 6/COPEB & $10 \mathrm{p} 15$ & Zinc-finger transcription factor & $\begin{array}{l}\text { Mutations and haplotype } \\
\text { insufficiency }\end{array}$ \\
\hline EZH2 & Enhancer of zeste homolog 2 & $7 q 35$ & Transcriptional memory & $\begin{array}{l}\text { Overexpressed in } \\
\text { aggressive Pca }\end{array}$ \\
\hline p27 & $\begin{array}{l}\text { Cyclin-dependent kinase inhibitor 1B } \\
\text { (p27, Kip1) }\end{array}$ & $12 \mathrm{p} 13$ & $\begin{array}{l}\text { Cyclin-dependent kinases } 2 \text { and } 4 \\
\text { inhibitor }\end{array}$ & $\begin{array}{l}\text { Downregulated with Pca } \\
\text { progression }\end{array}$ \\
\hline E-cadherin & E-cadherin & $16 q 22.1$ & Cell adhesion molecule & $\begin{array}{l}\text { Downregulated with Pca } \\
\text { progression }\end{array}$ \\
\hline
\end{tabular}

Pca $=$ prostate cancer PIN = prostatic intraepithelial neoplasia.

PTEN encodes a phosphatase active against both proteins and lipids, and is also commonly altered in prostate cancer progression. PTEN is believed to regulate the phosphatidylinositol $3^{\prime}$-kinase/protein kinase B (PI3/Akt) signaling pathway, and therefore mutations or alterations lead to tumor progression. ${ }^{66}$ As with many putative prostate cancer genes, PTEN is also associated with a number of other tumors. Mutations are less common than initially thought in prostate cancer; however, tumor suppressor activity may occur from the loss of one allele, leading to decreased expression of PTEN (i.e. haploinsufficiency). ${ }^{67} \mathrm{~A}$ number of other genes have also been associated with prostate cancer, including $p 27^{68-70}$ and $E$-cadherin. ${ }^{71,72}$ p53 mutations are late events in prostate cancer and tend to occur in advanced and metastatic prostate tumors. ${ }^{73}$

Recent advances in genomic and proteomic technologies suggest that molecular signatures of disease can be used for diagnosis, ${ }^{74,75}$ to predict survival, ${ }^{76,77}$ and to define novel molecular subtypes of disease. ${ }^{78}$ Several studies have used cDNA microarrays to characterize the gene expression profiles of prostate cancer in comparison with benign prostate disease and normal prostate tissue. ${ }^{79-84}$ Several interesting candidates include AMACR, Hepsin, KLF6, and EZH2. Alpha-methylacyl-CoA racemase (AMACR), an enzyme that plays an important role in bile acid biosynthesis and $\beta$-oxidation of branched-chain fatty acids, ${ }^{85,86}$ was determined to be upregulated in prostate cancer after examination of several independent gene expression data sets. ${ }^{79,80,82,87-89}$ These findings were supported by different groups on the protein level even when using different types of antibodies for immunoblot analysis and high-density tissue microarrays (TMA). ${ }^{79,87-89}$ Hepsin, a cell-surface serine protease, was determined to be overexpressed in localized and metastatic prostate cancer when compared to benign prostate or benign prostatic hyperplasia in several expression array experiments. ${ }^{79-81,90}$ By immunohistochemistry, hepsin was found to be highly expressed in PIN, suggesting that dysregulation of hepsin is an early event in the development of prostate cancer. $^{79}$ Kruppel-like factor $6(K L F 6)$ is a zinc-finger transcription factor of unknown function, which is mutated in a subset of human prostate cancer. ${ }^{91}$ Loss-of-heterozygosity analysis revealed that one $K L F 6$ allele is deleted in over $70 \%$ of primary prostate tumors. The retained allele is mutated in over $70 \%$ of these tumors. Functional studies suggest that wild-type KLF6 upregulates p21 (WAF1/CIP1) in a p53-independent manner and reduces cell proliferation, suggesting that KLF6 is a tumor suppressor gene. EZH2 (enhancer of zeste homolog 2), a member of the polycomb gene family, is a transcriptional repressor known to be active early in embryogenesis, ${ }^{92,93}$ showing decreased expression as cells differentiate. Recent work has demonstrated that EZH2 is highly overexpressed in metastatic hormone refractory prostate cancer as determined by cDNA and TMA analysis. ${ }^{94}$ EZH2 was also seen to be overexpressed in localized prostate cancers that have a higher risk of developing biochemical recurrence following radical prostatectomy, suggesting a possible diagnostic utility as a biomarker. These studies suggest a potential clinical application in the diagnosis of prostate cancer. However, like many other genes that have been mentioned, these alterations are not specific to prostate cancer and may be observed in other neoplasms.

\section{Androgen receptor and prostate cancer development}

The androgen receptor (AR) plays a critical role in prostate development. ${ }^{95}$ It has been known for many years that withdrawal of androgens leads to a rapid 
decline in prostate cancer growth with significant clinical response. This response is short-lived and tumor cells re-emerge, which are independent of androgen stimulation (androgen independent). $\mathrm{Nu}$ merous mutations have been identified in the androgen receptor gene (reviewed by Gelmann ${ }^{96}$ ). It has been hypothesized that through mutation, prostate cancers can grow with significantly lower circulating levels of androgens. In addition to common mutations, the amino-terminal domain encoded by exon one demonstrates a high percentage of polymorphic CAG repeats. ${ }^{97}$ Shorter CAG repeat lengths have been associated with a greater risk of developing prostate cancer and prostate cancer progression. ${ }^{98,99}$ Clinical trials such as the Prostate Cancer Prevention Trial (PCPT) are drawing to a close and should provide important clinical and molecular data on the role of decreasing the amount of available dehydroxytestosterone (DHT), the most active form of testosterone. Patients on this trial received long-term administration of the 5-hydroxyreductase inhibitor, fenasteride, which lowers levels of circulating DHT. One potential interesting result will be to observe the variability in response due to known polymorphisms in the 5-hydroxyreductase gene as over 50 -fold differences have been detected in the effect of fenasteride on 5-hydroxyreductase activity.

\section{Emerging molecular techniques: proteomics, laser capture microdissection, and bioinformatics}

Proteomics is also being applied to serum samples to identify unique profiles. ${ }^{100}$ This work promises to identify proteins that may be used for the prognosis and diagnosis of prostate cancer. Currently, several proteomic approaches are being used, including two-dimensional (2-D) electrophoresis and SEDITOF proteomics (recently reviewed by Adam et $a l^{75}$ ). The 2-D approach uses protein size and electrical charge to separate out proteins. Multiple gels from patients with and without prostate cancer are compared to help identify points that appear in one but not the other populations. Once unique proteins are identified, they can be isolated and further characterized using size and fragmentation patterns using proteases for protein digestion. This approach is laborious; however, new bioinformatics approaches may make virtual interpretation of proteins possible. The SEDI-TOF approach allows for the characterization of extremely small samples (eg, laser capture microdissection). The output is a protein profile that can be inferred. However, further characterization is not possible with this method. As in the recent example from Petricoin III et al, ${ }^{100}$ they were able to identify discrete prostate cancer-related protein bands. However, the identity of these bands is unknown and therefore is of limited use. Alternatively, one can image the use of protein or expression array profiles to identify patients at highest risk for developing a disease state (eg, prostate cancer) or even which patients would benefit from a treatment protocol.

Laser capture microdissection (LCM) is a technique that should allow for a more precise understanding of the cells' activity and represents an important improvement on standard microdissection techniques, which are limiting in the study of prostate cancer due to its infiltrative nature ${ }^{101} \mathrm{LCM}$ offers laser precision and can achieve transfer and isolation of single cells. LCM was developed by Emmert-Buck et $a^{102}$ at the National Cancer Institute (NCI) of the National Institutes of Health. LCM was born out of a need to isolate pure populations of tumor, normal, and dysplastic tissues as part of the Cancer Genome Anatomy Project (CGAP) project (http://cgap.nci.nih.gov). ${ }^{103,104}$ LCM now allows the investigator to ask questions regarding individual cells and the surrounding stromal tissues.

A rapidly emerging field, bioinformatics, is starting to alter the way research is being conducted. Using information from large databases, in silico studies can be conducted to discover and validate new candidate genes and pathways significant in areas such as the development of prostate cancer. For example, Rhodes et a ${ }^{105}$ recently identified lists of significant prostate cancer-related genes by performing a meta-analysis on publicly available cDNA expression array data sets. This study was also able to extrapolate prostate cancer-related pathways by piecing together data from multiple studies. This approach has now become available on an Internet-based website called ONCOMINE (www.oncomine.org) that allows users to perform a meta-analysis on genes of interest and contains links to other websites that provide information regarding their genes of interest. Pathologists will play an important role in this field due to our close relationship data information systems and a need for appropriate protection of patient-sensitive information available on our pathology data systems.

In summary, multiple factors contribute to the high incidence and prevalence of prostate cancer including race, ethnicity, diet, environment, widespread awareness through prostate-specific antigen screening and genetics. Linkage analysis has identified several candidate sites for hereditary prostate cancer gene loci. Molecular studies have also identified genes that are frequently altered in sporadic prostate cancer. It appears that due to the heterogeneity of prostate cancer, multiple genes may be involved in the neoplastic process.

\section{Acknowledgements}

We thank Allan Meeker for providing us with Figure 2 for this review. This work was supported by the Specialized Program of Research Excellence for Prostate Cancer (S.P.O.R.E.) NCI Grant P50CA69568 


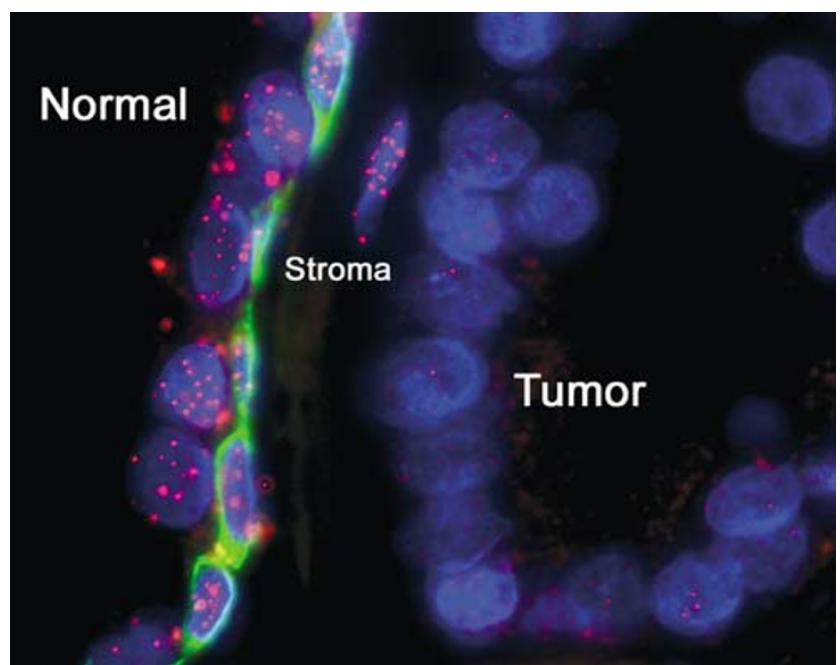

Figure 2 Direct Visualization of Telomere Shortening in Prostate Cancer. Telomere FISH signals (Red) within the cell nuclei (Blue) are diminished in prostate cancer compared to the adjacent normal gland. Green fluorescence indicates basal epithelial cells (basal cell-specific cytokeratin antibody).

(MAR) P50CA90381 (MAR) and P50CA58236 (AMDM), R01 CA84997(AMDM), KO8 CA78588 (AMDM), and R01AG21404 (MAR).

\section{References}

1 Morganti G, Gianferrari L, Cresseri A, et al. Recherches clinico-statistiques et genetiques sur les neoplasies de la prostate. Acta Genet 1956;6:304-305.

2 Lichtenstein P, Holm NV, Verkasalo PK, et al. Environmental and heritable factors in the causation of cancer-analyses of cohorts of twins from Sweden, Denmark, and Finland. N Engl J Med 2000;343:78-85.

3 Tavtigian SV, Simard J, Teng DH, et al. A candidate prostate cancer susceptibility gene at chromosome 17p. Nat Genet 2001;27:172-180.

4 Carpten J, Nupponen N, Isaacs S, et al. Germline mutations in the ribonuclease $\mathrm{L}$ gene in families showing linkage with HPC1. Nat Genet 2002;30: 181-184.

$5 \mathrm{Xu}$ J, Zheng SL, Komiya A, et al. Germline mutations and sequence variants of the macrophage scavenger receptor 1 gene are associated with prostate cancer risk. Nat Genet 2002;32:321-325.

6 Rebbeck TR, Walker AH, Zeigler-Johnson C, et al. Association of HPC2/ELAC2 genotypes and prostate cancer. Am J Hum Genet 2000;67:1014-1019.

7 Rokman A, Ikonen T, Mononen N, et al. ELAC2/HPC2 involvement in hereditary and sporadic prostate cancer. Cancer Res 2001;61:6038-6041.

8 Suarez BK, Gerhard DS, Lin J, et al. Polymorphisms in the prostate cancer susceptibility gene HPC2/ELAC2 in multiplex families and healthy controls. Cancer Res 2001;61:4982-4984.

9 Wang L, McDonnell SK, Elkins DA, et al. Role of HPC2/ ELAC2 in hereditary prostate cancer. Cancer Res 2001;61:6494-6499.

$10 \mathrm{Xu}$ J, Zheng SL, Carpten JD, et al. Evaluation of linkage and association of HPC2/ELAC2 in patients with familial or sporadic prostate cancer. Am J Hum Genet 2001;68:901-911.

11 Kerr IM, Brown RE. pppA2'p5'A2'p5'A: an inhibitor of protein synthesis synthesized with an enzyme fraction from interferon-treated cells. Proc Natl Acad Sci USA 1978;75:256-260.

12 Zhou A, Paranjape J, Brown TL, et al. Interferon action and apoptosis are defective in mice devoid of $2^{\prime}, 5^{\prime}$ oligoadenylate-dependent RNase L. EMBO J 1997;16: 6355-6363.

13 Casey G, Neville PJ, Plummer SJ, et al. RNASEL Arg462Gln variant is implicated in up to $13 \%$ of prostate cancer cases. Nat Genet 2002;32:581-583.

14 Rennert H, Bercovich D, Hubert A, et al. A novel founder mutation in the RNASEL gene, 471delAAAG, is associated with prostate cancer in Ashkenazi Jews. Am J Hum Genet 2002;71:981-984.

15 Rokman A, Ikonen T, Seppala EH, et al. Germline alterations of the RNASEL gene, a candidate HPC1 gene at 1q25, in patients and families with prostate cancer. Am J Hum Genet 2002;70:1299-1304.

16 Wang L, McDonnell SK, Elkins DA, et al. Analysis of the RNASEL gene in familial and sporadic prostate cancer. Am J Hum Genet 2002;71:116-123.

17 Bova GS, Partin AW, Isaacs SD, et al. Biological aggressiveness of hereditary prostate cancer: long-term evaluation following radical prostatectomy. J Urol 1998;160:660-663.

18 Ross RK, Pike MC, Coetzee GA, et al. Androgen metabolism and prostate cancer: establishing a model of genetic susceptibility. Cancer Res 1998;58: 4497-4504.

$19 \mathrm{Xu}$ J, Zheng SL, Turner A, et al. Associations between hOGG1 sequence variants and prostate cancer susceptibility. Cancer Res 2002;62:2253-2257.

20 Rich AR. On the frequency of occurrence of occult carcinoma of the prostate. J Urol 1934;33:215-223.

21 Moore RA. The evolution and involution of the prostate gland. Am J Pathol 1936;12:599-624.

22 Franks LM. Atrophy and hyperplasia in the prostate proper. J Pathol Bacteriol 1954;68:617-621.

23 McNeal JE. Normal histology of the prostate. Am J Surg Pathol 1988;12:619-633.

24 Weinstein RS, Gardner WA. Pathology and pathobiology of the urinary bladder and prostate. Monographs in Pathology 1992, Vol. xi, No. 34. Williams \& Wilkins: Baltimore, MD, p221

25 Feneley MR, Young MP, Chinyama C, et al. Ki-67 expression in early prostate cancer and associated pathological lesions. J Clin Pathol 1996;49: 741-748.

26 Ruska KM, Sauvageot J, Epstein JI. Histology and cellular kinetics of prostatic atrophy. Am J Surg Pathol 1998;22:1073-1077.

27 De Marzo AM, Marchi VL, Epstein JI, et al. Proliferative inflammatory atrophy of the prostate: implications for prostatic carcinogenesis. Am J Pathol 1999;155:1985-1992.

28 Putzi MJ, De Marzo AM. Morphologic transitions between proliferative inflammatory atrophy and highgrade prostatic intraepithelial neoplasia. Urology 2000;56:828-832.

29 Liavag I. Atrophy and regeneration in the pathogenesis of prostatic carcinoma. Acta Pathol Microbiol Scand 1968;73:338-350.

30 Montironi R, Mazzucchelli R, Scarpelli M. Precancerous lesions and conditions of the prostate: from 
morphological and biological characterization to chemoprevention. Ann NY Acad Sci 2002;963: 169-184.

31 Shah R, Mucci NR, Amin A, et al. Postatrophic hyperplasia of the prostate gland: neoplastic precursor or innocent bystander? Am J Pathol 2001;158: 1767-1773.

32 Macoska JA, Trybus TM, Wojno KJ. 8p22 loss concurrent with 8c gain is associated with poor outcome in prostate cancer. Urology 2000;55:776-782.

33 Tsujimoto $\mathrm{Y}$, Takayama $\mathrm{H}$, Nonomura $\mathrm{N}$, et al. Postatrophic hyperplasia of the prostate in Japan: histologic and immunohistochemical features and p53 gene mutation analysis. Prostate 2002;52: 279-287.

34 Nakayama M, Bennett CJ, Hicks JL, et al. Hypermethylation of the human glutathione $S$-transferase-pi gene (GSTP1) CpG island is present in a subset of proliferative inflammatory atrophy lesions but not in normal or hyperplastic epithelium of the prostate: a detailed study using laser-capture microdissection. Am J Pathol 2003;163:923-933.

35 Parsons JK, Nelson CP, Gage WR, et al. GSTP1 expression in normal, preneoplastic, and neoplastic human prostate tissue. Prostate 2001;49:30-37.

36 Zha S, Gage WR, Sauvageot J, et al. Cyclooxygenase-2 is up-regulated in proliferative inflammatory atrophy of the prostate, but not in prostate carcinoma. Cancer Res 2001;61:8617-8623.

37 van Leenders GJ, Gage WR, Hicks JL, et al. Intermediate cells in human prostate epithelium are enriched in proliferative inflammatory atrophy. Am J Pathol 2003;162:1529-1537.

38 Verhagen AP, Ramaekers FC, Aalders TW, et al. Colocalization of basal and luminal cell-type cytokeratins in human prostate cancer. Cancer Res 1992;52: 6182-6187.

39 De Marzo AM, Meeker AK, Epstein JI, et al. Prostate stem cell compartments: expression of the cell cycle inhibitor p27Kip1 in normal, hyperplastic, and neoplastic cells. Am J Pathol 1998;153:911-919.

40 De Marzo AM, Nelson WG, Meeker AK, et al. Stem cell features of benign and malignant prostate epithelial cells. J Urol 1998;160(6 Part 2):2381-2392.

41 van Leenders G, Dijkman H, Hulsbergen-van de Kaa C, et al. Demonstration of intermediate cells during human prostate epithelial differentiation in situ and in vitro using triple-staining confocal scanning microscopy. Lab Invest 2000;80:1251-1258.

42 Cahill DP, Kinzler KW, Vogelstein B, et al. Genetic instability and Darwinian selection in tumours. Trends Cell Biol 1999;9:M57-M60.

43 Counter CM, Avilion AA, LeFeuvre CE, et al. Telomere shortening associated with chromosome instability is arrested in immortal cells which express telomerase activity. EMBO J 1992;11:1921-1929.

44 Hackett JA, Greider CW. Balancing instability: dual roles for telomerase and telomere dysfunction in tumorigenesis. Oncogene 2002;21:619-626.

45 McClintock B. The stability of broken ends of chromosomes in Zea mays. Genetics 1941;26:234-282.

46 Blasco MA, Lee HW, Hande MP, et al. Telomere shortening and tumor formation by mouse cells lacking telomerase RNA. Cell 1997;91:25-34.

47 Artandi SE, Chang S, Lee SL, et al. Telomere dysfunction promotes non-reciprocal translocations and epithelial cancers in mice. Nature 2000;406:641-645.
48 Sommerfeld HJ, Meeker AK, Piatyszek MA, et al. Telomerase activity: a prevalent marker of malignant human prostate tissue. Cancer Res 1996;56:218-222.

49 Donaldson L, Fordyce C, Gilliland F, et al. Association between outcome and telomere DNA content in prostate cancer. J Urol 1999;162:1788-1792.

50 O'Shaughnessy JA, Kelloff GJ, Gordon GB, et al. Treatment and prevention of intraepithelial neoplasia: an important target for accelerated new agent development. Clin Cancer Res 2002;8:314-346.

51 Shih IM, Zhou W, Goodman SN, et al. Evidence that genetic instability occurs at an early stage of colorectal tumorigenesis. Cancer Res 2001;61:818-822.

52 Meeker AK, Gage WR, Hicks JL, et al. Telomere length assessment in human archival tissues: combined telomere fluorescence in situ hybridization and immunostaining. Am J Pathol 2002;160:1259-1268.

53 Cher ML, MacGrogan D, Bookstein R, et al. Comparative genomic hybridization, allelic imbalance, and fluorescence in situ hybridization on chromosome 8 in prostate cancer. Genes Chromosomes Cancer 1994;11:153-162.

54 Joos S, Bergerheim US, Pan Y, et al. Mapping of chromosomal gains and losses in prostate cancer by comparative genomic hybridization. Genes Chromosomes Cancer 1995;14:267-276.

55 Visakorpi T, Kallioniemi AH, Syvanen AC, et al. Genetic changes in primary and recurrent prostate cancer by comparative genomic hybridization. Cancer Res 1995;55:342-347.

56 Nupponen NN, Kakkola L, Koivisto P, et al. Genetic alterations in hormone-refractory recurrent prostate carcinomas. Am J Pathol 1998;153:141-148.

57 Lee WH, Morton RA, Epstein JI, et al. Cytidine methylation of regulatory sequences near the pi-class glutathione S-transferase gene accompanies human prostatic carcinogenesis. Proc Natl Acad Sci USA 1994;91:11733-11737.

58 Millar DS, Ow KK, Paul CL, et al. Detailed methylation analysis of the glutathione S-transferase pi (GSTP1) gene in prostate cancer. Oncogene 1999;18:1313-1324.

59 Lin X, Tascilar M, Lee WH, et al. GSTP1 CpG island hypermethylation is responsible for the absence of GSTP1 expression in human prostate cancer cells. Am J Pathol 2001;159:1815-1826.

60 He WW, Sciavolino PJ, Wing J, et al. A novel human prostate-specific, androgen-regulated homeobox gene (NKX3.1) that maps to $8 \mathrm{p} 21$, a region frequently deleted in prostate cancer. Genomics 1997;43:69-77.

61 Voeller HJ, Augustus M, Madike V, et al. Coding region of NKX3.1, a prostate-specific homeobox gene on 8p21, is not mutated in human prostate cancers. Cancer Res 1997;57:4455-4459.

62 Bowen C, Bubendorf L, Voeller HJ, et al. Loss of NKX3.1 expression in human prostate cancers correlates with tumor progression. Cancer Res 2000;60:6111-6115.

63 Kim MJ, Bhatia-Gaur R, Banach-Petrosky WA, et al. Nkx3.1 mutant mice recapitulate early stages of prostate carcinogenesis. Cancer Res 2002;62:29993004.

$64 \mathrm{Li} \mathrm{J}$, Yen C, Liaw D, et al. PTEN, a putative protein tyrosine phosphatase gene mutated in human brain, breast, and prostate cancer. Science 1997;275:19431947.

65 Steck PA, Pershouse MA, Jasser SA, et al. Identification of a candidate tumour suppressor gene, MMAC1, 
at chromosome 10q23.3 that is mutated in multiple advanced cancers. Nat Genet 1997;15:356-362.

$66 \mathrm{Wu}$ X, Senechal K, Neshat MS, et al. The PTEN/ MMAC1 tumor suppressor phosphatase functions as a negative regulator of the phosphoinositide 3-kinase/ Akt pathway. Proc Natl Acad Sci USA 1998;95: 15587-15591.

67 Kwabi-Addo B, Giri D, Schmidt K, et al. Haploinsufficiency of the Pten tumor suppressor gene promotes prostate cancer progression. Proc Natl Acad Sci USA 2001;98:11563-11568.

68 Guo Y, Sklar GN, Borkowski A, et al. Loss of the cyclindependent kinase inhibitor p27(Kip1) protein in human prostate cancer correlates with tumor grade. Clin Cancer Res 1997;3(12 Part 1):2269-2274.

69 Cordon-Cardo C, Koff A, Drobnjak M, et al. Distinct altered patterns of p27KIP1 gene expression in benign prostatic hyperplasia and prostatic carcinoma. J Natl Cancer Inst 1998;90:1284-1291.

70 Yang RM, Naitoh J, Murphy M, et al. Low p27 expression predicts poor disease-free survival in patients with prostate cancer. J Urol 1998;159:941-945.

71 Umbas R, Schalken JA, Aalders TW, et al. Expression of the cellular adhesion molecule E-cadherin is reduced or absent in high-grade prostate cancer. Cancer Res 1992;52:5104-5109.

72 Otto T, Rembrink K, Goepel M, et al. E-cadherin: a marker for differentiation and invasiveness in prostatic carcinoma. Urol Res 1993;21:359-362.

73 Heidenberg HB, Sesterhenn IA, Gaddipati JP, et al. Alteration of the tumor suppressor gene p53 in a high fraction of hormone refractory prostate cancer. J Urol 1995;154(2 Part 1):414-421.

74 Golub TR, Slonim DK, Tamayo P, et al. Molecular classification of cancer: class discovery and class prediction by gene expression monitoring. Science 1999;286:531-537.

75 Adam BL, Qu Y, Davis JW, et al. Serum protein fingerprinting coupled with a pattern-matching algorithm distinguishes prostate cancer from benign prostate hyperplasia and healthy men. Cancer Res 2002;62:3609-3614.

76 Takahashi M, Rhodes DR, Furge KA, et al. Gene expression profiling of clear cell renal cell carcinoma: gene identification and prognostic classification. Proc Natl Acad Sci USA 2001;98:9754-9759.

77 Rosenwald A, Wright G, Chan WC, et al. The use of molecular profiling to predict survival after chemotherapy for diffuse large-B-cell lymphoma. N Engl J Med 2002;346:1937-1947.

78 Perou CM, Sorlie T, Eisen MB, et al. Molecular portraits of human breast tumours. Nature 2000;406: 747-752.

79 Dhanasekaran SM, Barrette TR, Ghosh D, et al. Delineation of prognostic biomarkers in prostate cancer. Nature 2001;412:822-826.

80 Luo J, Duggan DJ, Chen Y, et al. Human prostate cancer and benign prostatic hyperplasia: molecular dissection by gene expression profiling. Cancer Res 2001;61:4683-4688.

81 Magee JA, Araki T, Patil S, et al. Expression profiling reveals hepsin overexpression in prostate cancer. Cancer Res 2001;61:5692-5696.

82 Welsh JB, Sapinoso LM, Su AI, et al. Analysis of gene expression identifies candidate markers and pharmacological targets in prostate cancer. Cancer Res 2001;61:5974-5978.
83 Luo JH, Yu YP, Cieply K, et al. Gene expression analysis of prostate cancers. Mol Carcinogen 2002;33:25-35

84 Singh D, Febbo PG, Ross K, et al. Gene expression correlates of clinical prostate cancer behavior. Cancer Cell 2002;1:203-209.

85 Ferdinandusse S, Denis S, IJlst L, et al. Subcellular localization and physiological role of alpha-methylacyl-CoA racemase. J Lipid Res 2000;41:1890-1896.

86 Kotti TJ, Savolainen K, Helander HM, et al. In mouse alpha -methylacyl-CoA racemase, the same gene product is simultaneously located in mitochondria and peroxisomes. J Biol Chem 2000;275:20887-20895.

87 Jiang Z, Woda BA, Rock KL, et al. P504S: a new molecular marker for the detection of prostate carcinoma. Am J Surg Pathol 2001;25:1397-1404

88 Luo J, Zha S, Gage WR, et al. Alpha-methylacyl-CoA racemase: a new molecular marker for prostate cancer. Cancer Res 2002;62:2220-2226.

89 Rubin MA, Zhou M, Dhanasekaran SM, et al. Alphamethylacyl coenzyme A racemase as a tissue biomarker for prostate cancer. JAMA 2002;287:1662-1670.

90 Stamey TA, Warrington JA, Caldwell MC, et al. Molecular genetic profiling of Gleason grade $4 / 5$ prostate cancers compared to benign prostatic hyperplasia. J Urol 2001;166:2171-2177.

91 Narla G, Heath KE, Reeves HL, et al. KLF6, a candidate tumor suppressor gene mutated in prostate cancer. Science 2001;294:2563-2566.

92 Francis NJ, Kingston RE. Mechanisms of transcriptional memory. Nat Rev Mol Cell Biol 2001;2: 409-421.

93 Mahmoudi T, Verrijzer CP. Chromatin silencing and activation by Polycomb and trithorax group proteins. Oncogene 2001;20:3055-3066.

94 Varambally S, Dhanasekaran SM, Zhou M, et al. The polycomb group protein EZH2 is involved in progression of prostate cancer. Nature 2002;419:624-629.

95 Yong EL, Lim J, Qi W, et al. Molecular basis of androgen receptor diseases. Ann Med 2000;32:15-22.

96 Gelmann EP. Molecular biology of the androgen receptor. J Clin Oncol 2002;20:3001-3015.

97 Trapman J, Cleutjens KB. Androgen-regulated gene expression in prostate cancer. Semin Cancer Biol 1997;8:29-36.

98 Schoenberg MP, Hakimi JM, Wang S, et al. Microsatellite mutation (CAG24 $\rightarrow 18)$ in the androgen receptor gene in human prostate cancer. Biochem Biophys Res Commun 1994;198:74-80.

99 Giovannucci E, Stampfer MJ, Krithivas K, et al. The CAG repeat within the androgen receptor gene and its relationship to prostate cancer. Proc Natl Acad Sci USA 1997;94:3320-3323.

100 Petricoin. III EF, Ornstein DK, Paweletz CP, et al. Serum proteomic patterns for detection of prostate cancer. J Natl Cancer Inst 2002;94:1576-1578.

101 Rubin MA. Tech. Sight. Understanding disease cell by cell. Science 2002;296:1329-1330.

102 Emmert-Buck MR, Bonner RF, Smith PD, et al. Laser capture microdissection. Science 1996;274: 998-1001.

103 Strausberg RL. The Cancer Genome Anatomy Project: new resources for reading the molecular signatures of cancer. J Pathol 2001;195:31-40.

104 Strausberg RL, Greenhut SF, Grouse LH, et al. In silico analysis of cancer through the Cancer Genome Anatomy Project. Trends Cell Biol 2001;11:S66-S71. 
105 Rhodes DR, Barrette TR, Rubin MA, et al. Meta-analysis of microarrays: inter-study validation of gene expression profiles reveals pathway dysregulation in prostate cancer. Cancer Res 2002;62: 4427-4433.

106 Smith JR, Freije D, Carpten JD, et al. Major susceptibility locus for prostate cancer on chromosome 1 suggested by a genome-wide search. Science 1996;274:1371-1374.

107 Berthon P, Valeri A, Cohen-Akenine A, et al. Predisposing gene for early-onset prostate cancer, localized

on chromosome 1q42.2-43. Am J Hum Genet 1998;62: 1416-1424.

108 Gibbs M, Stanford JL, McIndoe RA, et al. Evidence for a rare prostate cancer-susceptibility locus at chromosome 1p36. Am J Hum Genet 1999;64:776-787.

$109 \mathrm{Xu}$ J, Meyers D, Freije D, et al. Evidence for a prostate cancer susceptibility locus on the X chromosome. Nat Genet 1998;20:175-179.

110 Berry R, Schroeder JJ, French AJ, et al. Evidence for a prostate cancer-susceptibility locus on chromosome 20. Am J Hum Genet 2000;67:82-91. 